\title{
Knowledge Management: The Case for Kenya
}

\author{
Zachary Mosoti \& Becky Masheka
}

\begin{abstract}
In the rapidly changing environment and the high technology atmosphere of the $21^{\text {st }}$ century, organizations are becoming more innovative than ever before. Most organizations in the developed and the developing world are opting for change in management, looking for ways to improve their ability to create new ideas and to develop the best environment for creation of ideas. Knowledge management is now recognized as an organization's most valuable asset. Because knowledge is a complex asset, it must be managed in a different way unlike other resources. In this research, we examine how knowledge management practices are carried out and their contribution to the development in Kenya and Africa.
\end{abstract}

Key words: Knowledge, management, technology, organizations, change

\section{Background}

Knowledge is dynamic. In recent times a new branch of management has emerged called Knowledge Management (KM) (Hicks et al, 2006). It is meant to achieve breakthrough in business performance through the synergy of people, processes, and technology. It also focuses on the management of change, uncertainty, and complexity. Again it serves as the source and stock of knowledge and the flow of knowledge. This includes knowledge creation, sharing and application to create and or sustain organizational value and competitive advantage (Liew, 2007).

According to Wickramasinghe (2003), in its broadest application KM refers to how firms acquire, apply and store their own intellectual capital. From a theoretical standpoint, Wickramasinghe et al. (2003:298) argue:

KM refer to the information systems adopted and designed, which efficiently and effectively leverage the collective experience and knowledge of employees to support information processing needs, as well as enabling and facilitating sense-making activities of knowledge workers.

In this study, however, knowledge management is getting the right information to the right people at the right time, and helping people create knowledge, share and act upon information in ways that will measurably improve their performance (Warren et al_2006). In other words, it is to utilize individual expertise to get maximum return for an organization.

Knowledge management has several areas that include knowledge management systems, knowledge management practices, knowledge management broker and others. The paper is concerned with Knowledge Management Practices (KMP). Hicks et al. (2006:19) articulate that knowledge management has three fundamental concepts, which include: data, information and knowledge. They explain that data is a set of records and represents 
a fact or statement of event and information is formed when we attach semantics to the data; when intelligence is attached to the information, then knowledge is created (Govil, 2007). The relationship between data, information and knowledge is what is referred to as "Knowledge Hierarchy." In knowledge hierarchy data is transformed into information, and information into knowledge.

While some scholars are discussing knowledge in terms of knowledge hierarchy concept, others, like Liew (2007) advocate for data management, information management and knowledge management. He posits that data management is the capture, storage, structure, compilation, retrieval, and analysis of records. Further, "It is the reconstruction of recent or historical events as inputs for decision-making and problem solving." Liew (2007:206) also contends that:

\footnotetext{
"Information management includes reconstructing a picture of historical events, collecting current or recent market intelligence, as well as projecting possible future events (forecasting and scenario planning), and of course analysis for decision making and problem solving. Thereafter, action can be taken and then reviewed. Knowledge management is how an organization acquires, stores and applies its own intellectual capital."
}

\section{Old World of Business versus New World of Business}

Malthotra et al. (2000) and Prescott et al. (2001) have identified two versions of world of business: old world of business and new world of business. In the old world of business because of its predictable environments, the success could be planned and organizational performance obtained through the use of information. Malthotra (1998:12) argues that, "This period of the world of competence is based on 'information' as the strategic asset and the emphasis is on controlling the behavior of organizational agents toward fulfillment of pre-specified organizational goals and objectives". On the contrary, high levels of uncertainty and inability to predict the future characterize the "new world of business" which includes the "current world of business." The author calls it the world of re-everything.

According to Prescott et al. (2001) the comparison of the "old world of business" and "new world of business" shed light on changes that organizations have made and the vision of changes organizations should undertake in application of KMP.

Prescott et al. (2001) shed light on the use of knowledge management in the two world of business by stating that there was too much routine report generation and many nonactionable requests in the old world of business. In this environment the tendency was to be too reactive and too far removed from the core strategy and the key planning activity. In contrast, the new world of business is moving to a new organizational structure where we are making effort from the beginning by having the business intelligence activity embedded into strategy development. In this new world of business, knowledge management becomes the primary resources and competitive advantage for individual managers and their organizations. (Asllani and Luthans (2003), and Sharp (2004) contend that, "We live in a world of hyper-competition, constant, relentless change, rapid innovation and increasing market risk". People can choose to watch as their world passes 
them by, or they can choose to become future entrepreneurs, able to spot the trends, analyze what it means, and determine an action plan that let them master their future.

\section{Old Knowledge Management versus New Knowledge Management}

Some scholars divide Knowledge Management (KM) into old KM and new KM (Thitithananon et al, 2007). First, the old KM assumed that knowledge of an organization already existed within the institution's boundaries so the intellectual capital of the whole organization could depend on the knowledge of arriving and departing employees, especially in the form of tacit knowledge. This means, getting the right information to the right people at the right time. Second, the new KM assumes that knowledge of all institutions not only exists within the organization's boundaries; but, knowledge is able to be created by the adaptive requirements of the organization itself continuously in order to compete with other competitors.

Other scholars like McElroy discuss KM in terms of first and second generation (Laszlo, 2001). The first generation KM focuses on knowledge sharing - how to distribute existing organizational knowledge, usually through technology. Second generation KM focuses on knowledge creation - how to satisfy organizational needs for new knowledge, usually through processes of learning and innovation. Pollard insists that most companies had adopted KM in the mid-1990s and then limited the first generations KM from 1995 to 2005 and the second generation KM from 2005 to 2015 . He argues that the firstgeneration KM (called old KM) has vainly sought one-size fits-all integrated enterprise solutions, which are complicated to use and expensive to change and which focus on content and collection. Second-generation KM (called new KM) focuses on simple, lightweight, cheap, intuitive, stand-alone applications, which are easy to use, add or change and which focus on context and connection.

The first generation KM viewed KM in supply side only and it was only to capture, codify and share knowledge; but, the second generation views KM in both supply side and demand side. McElroy insists that in the second generation, KM is not an application of information technology (IT); rather, KM sometimes uses IT to help it have impact on the social dynamics of knowledge processing. Knowledge Management enhances an organization's capacity to adapt by improving its ability to learn and innovate and to detect and solve problems. This is illustrated on figure 1.1 below.

Figure 1 showing $2^{\text {nd }}$ generation knowledge management (Adapted from Laszlo, 2001). 


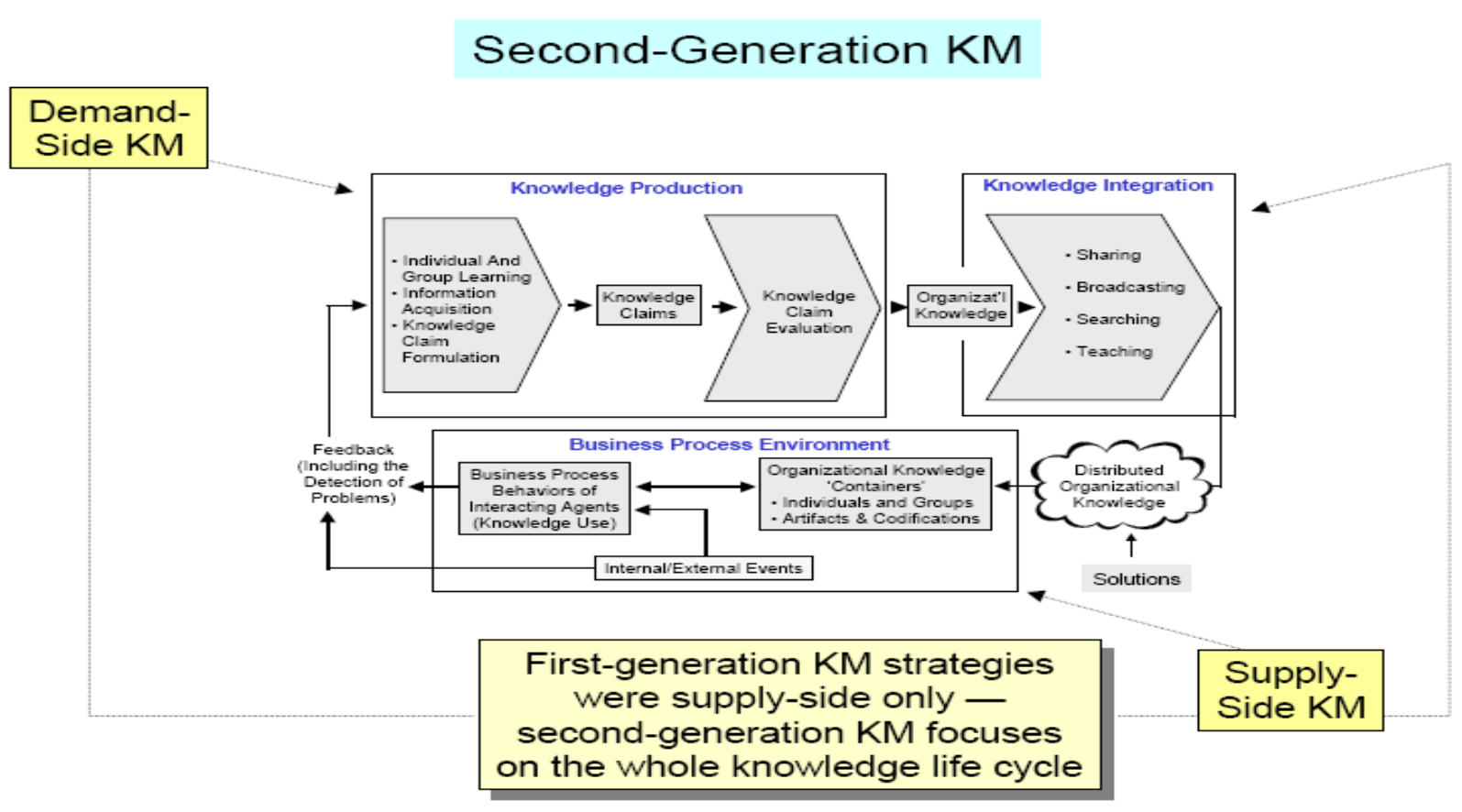

\section{Knowledge Management: A Collective Move}

Many organizations are agreeing that to grow, stay competitive and survive, they have to constantly change their strategies to meet new business demands and this explains the growth of interest in knowledge management over the last decade. Those organizations that work as if their environment is still stable (old world of business), not only are they losing the competitive advantage; but also they are facing huge financial losses. For example, according to Al-Ain (2007) "Fortune 500 companies lose at least $\$ 31.5$ billion a year by failing to share knowledge". They also lose knowledge of best practice in a specific area of operations as a result of a key employee's departure and finally they lose in relationship with a key client or supplier or a sponsor by the departure of key individuals.

Several studies done, especially in developing countries have proposed Knowledge Management frameworks and models to help organizations improve their performance and to gain competitive advantage. All these models and frameworks insist on two kinds of knowledge: explicit knowledge and implicit knowledge. They also tackle the enabler factors and the process. Enabler factors such as: technology, leadership, strategy and organizational culture (control, time, motivation and commitment). The process is life cycle KMP of capture, organize, share, use and re-use to produce organization's performance and to gain competitive advantage.

It is argued that companies are having difficulties in tackling KM. However, those that are advanced in implementing knowledge management are reaping benefits. Knowledge Management practice has great influence in transforming the way organizations do their 
business and the awareness of knowledge management might depend on the size of the organization.

Malhotra (2000) recognizes that there are many aspects of KM that need to be explored to better understand how KMP can be applied. The exploration of KMP practice in Kenya helps the study better understand how KMP can apply to an organization in relation to its goals and strategy in two levels that contributes to the originality of this work. The first level in a developing country like Kenya and the second level is the status of the organization where KMP is applied: for non-profit organization and for profit organization.

\section{Knowledge Management in Africa}

Africa is termed as a "Knowledge Society" (Ondari \& Minishi-Majanja (2007). Drucker contends that the basic economic source in Africa would no longer be capital or natural resources or even labor but knowledge. This means that Africa is endowed with Indigenous Knowledge that is needed to capture, share and transfer knowledge. Indigenous knowledge (IK) is defined as the local knowledge that is unique to a given culture or society and forms the basis for decision making within communities (Ndugo et al, (2007). The drive to manage knowledge in African culture is characterized by an old African proverb that states "in Africa, when an old man dies, the entire library is burnt." In this, there is need in Africa to capture indigenous knowledge, share and transfer it by networking between countries.

An electronic network has been created to foster connections across varying boundaries to create a 'knowledge bank' that links expertise with demand. Among the knowledge bank is Knowledge Management Africa (KMA) which has become knowledge engine that drives appropriate development solutions for Africa, Banhenyi (2007). The mission of KMA is to promote the use of Africa's collective knowledge as a key development resource and establish KM platforms that will create access to existing networks and facilitate the sharing and utilization of knowledge across all sectors.

KMA organizes biennial conferences in different countries to boost the implementation of KM in Africa. The 'KMA 2007' was the second biennial conference held in Nairobi from July 17 to 19, 2007 and brought together diverse international development finance institutions, sector professionals and civil-society organizations. The conference aimed at synthesizing coalitions of independent and interdependent knowledge networks and practitioners into a conduit for the cooperative pursuit of mutual advantage to rival the countervailing dominance of trade, finance and investment by affluent countries having the muscle of strong, hi-tech economies.

Adjacent to KMA, is Global Development Network (GDNet) that organizes various workshops in Africa. The Knowledge Sharing for Development: Africa Regional Program workshop was held in Cairo-Egypt on February 27-28, 2005. The workshop targeted the following three objectives:

First, to share experience - explore a range of tools for research communications and knowledge sharing. Second, to meet research communication and knowledge sharing challenges - identify 
practical solutions and insights. Finally, to build relationships among professionals with similar interests in research, communication and knowledge sharing.

The African Medical and Research Foundation (AMREF) is an organization operating seven country programmes in Kenya, Uganda, Ethiopia, Somalia, Tanzania, South Sudan, and South Africa. With its headquarters in Nairobi-Kenya, AMREF works though Africa's communities, health systems and governments, generating and applying knowledge that contributes to closing the gaps that prevent people from exercising their basic right to health (Ireri \& Wairagu, 2007). AMREF's strategy is to facilitate the development of innovative models for community participation in the improvement of health. It recognizes knowledge as a valuable resource that deserves to be consciously captured and managed to facilitate sharing of experiences and lessons learnt from different programmes both internally and externally. If this can only be implemented in Africa, it will be considered as an advanced big step to the second generation of Knowledge management whereby knowledge must not only be captured and shared but also be produced. In fact Kenya has 83 non profit organizations and 277 registered profit organizations as indicated on the 2007 Business D,irectory and this offers the need to study whether knowledge management is implemented. With the above background in mind the study focused on the knowledge management practices in organizations in Nairobi-Kenya.

\section{Data, Information and Knowledge}

The term knowledge was used very long ago by ancient scholars such as Plato and Aristotle. Scholars have attempted to redefine knowledge and explain its place in society. Sigala and Chalkiti (2007) observe that knowledge falls into two schools of thought, namely - rationalism and empiricism. Rationalism supports that knowledge is a "justified true belief", while empiricism argues that knowledge is created on an ongoing basis from experience. More recent work provides a build-up approach for understanding what knowledge is and how it is developed. This new perspective can be summarized into the categorization of knowledge's building blocks which follows: data organized in meaningful format from information, which in turn is transformed into knowledge if the latter is purposefully attached to an operating function.

To define knowledge, scholars define it with its connections concepts that are Data and Information called "Knowledge Hierarchy." Hicks et al. (2007) argues that "in this paradigm, each level in the hierarchy builds on the one below it, so data are required to create information, and information is required to create knowledge. The knowledge hierarchy depicts the conventional concept of knowledge transformations, where data is transformed into information, and information is transformed into knowledge.

Though there are different definitions of data, information, and knowledge this study has adopted Liew's definition of data, information, and knowledge. Liew (2007) defines data, information, and knowledge in the following manner:

Data are recorded (captured and stored) symbols (text and/or verbal) and signal (still and/or video) readings. Information is a message that contains relevant meaning, implication, or input for decision and/or action. Information comes from both current (communication) and historical 
(processed data or 'reconstructed picture') sources. Knowledge is the (1) cognition or recognition (know-what), (2) capacity to act (know-how), and (3) understanding (know-why) that resides or is contained within the mind or in the brain. The purpose of knowledge is to better our lives.

Figure 2 showing understanding knowledge, information, and data (Adapted from Liew, 2007).

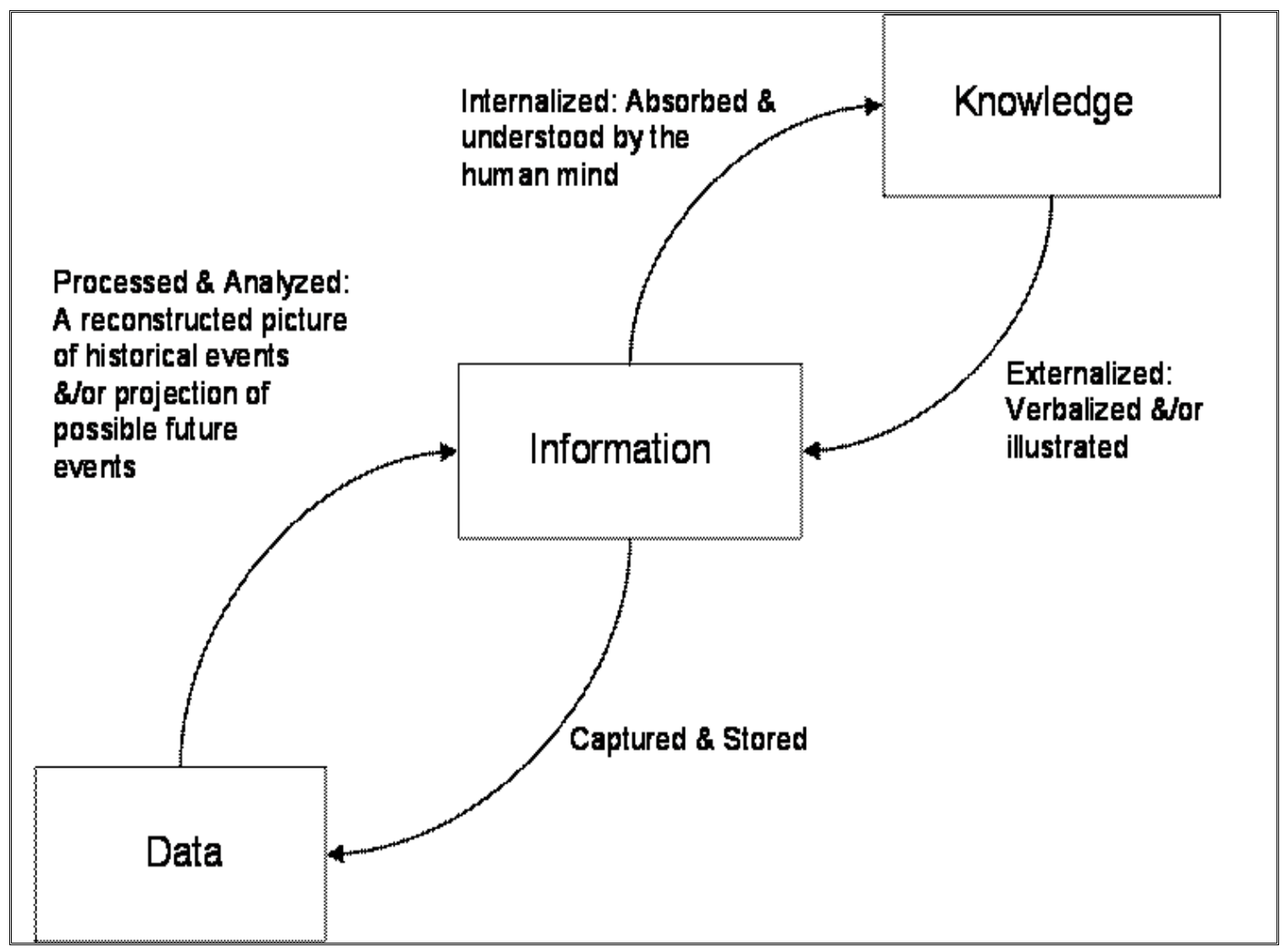

Organizations deal with data, information and Knowledge on daily basis. The relationship between the three is relevant. Davenport \& Prusak (1998) argue that the three are not interchangeable concepts, understanding what they are and how organizations get from one to another is essential to doing knowledge work successfully (Liew, 2007). To understand the relation amongst the three, Liew gives the example of a book. A book is data stored in a library; it is information to readers and knowledge to the writer. This relationship is built on the use of the three elements.

Polanyi (2004) gives another relationship that builds on how the rules are followed and call it "a hierarchy of knowing." He states that the lowest level of knowing is to follow rules which can be controlled by the subject itself. Skill which is the next level means to follow rules which are established by a social context outside the individual, Know-How; 
and the highest level is to be able to (and be allowed to) change the rules, competence or perhaps better in contemporary English expertise. Each level contains both tacit and focal knowing (Cortada \& Woods, 1999).

\section{Tacit and Explicit knowledge}

According to Stover (2004), the phrase "tacit knowledge" was coined by Polanyi, an influential philosopher of epistemology (Stover, 2004). But in recent years it has been used by management theorists as a key piece in the process of KM. Tacit knowledge is contrasted with explicit knowledge, which is expressed knowledge that is communicated to others. Polanyi stated that knowledge will be created if we convert one type of knowledge to another (Cortada \& Woods 1999). The conversion can be tacit-to-tacit (e.g. watching somebody, then doing it), tacit-to-explicit (e.g. doing it, then describing it), or explicit-to-explicit (reading about it, then describing it). The result, whenever knowledge translates from one form to another, is liberated energy, innovation, and performance. He recognizes that tacit knowledge lives in our hunches, intuition, emotions, values, and beliefs.

Both explicit and tacit knowledge are rooted in action, experience, and involvement in a specific context. Tacit knowledge is further devised into cognitive and technical elements. The cognitive elements refers to an individual's mental models consisting of mental maps, beliefs, paradigms and viewpoints; whereas, the technical component consists of concrete know-how, crafts, and skills that apply to a specific context. The explicit knowledge is in its turn, articulated, codified and communicated in symbolic form and or natural language.

\section{Knowledge Management Factors}

For the purpose of this study, two main variables to knowledge management: Enablers' factors and process have been considered. Enablers' factors are technology, organizational culture, and organizational leadership. Process is about the knowledge life cycle from identification of knowledge to improving organizational performance. Tacit and explicit knowledge is the key aspect in the life cycle. To manage knowledge well it is relevant to understand what knowledge is and what it entails. There is a great relationship between data, information, and knowledge as earlier mentioned (Hick et al, 2007). Others distinguish between raw information and knowledge. They state that raw information is widely available to a number of organizations, but only some organizations are able to convert them into relevant knowledge and to use this knowledge to achieve their aims. (Holvand, 2003).

Reviewing knowledge management and the organization's perspective, Alrawi \& Al-Ain (2007) bring the concept of "resource-based'. The later considers organizational resources and capabilities as the principal source of achieving and sustaining competitive advantage. Also, they found that most articles continue to focus on developing and implementing KMP database, tools and techniques. How KMP interacts with existing organization structures and how KMP can apply to an organization in relation to its goals and strategy has not been taken into consideration. 
Since knowledge is the key source of competitive advantage, organizations are missing out on a huge opportunity when their use of incentives does not take organizational culture, or personal motivational factors into account. Gammelgaard, (2007) argues that individuals are disposed to hoard the knowledge they possess. And therefore, as people leave, organizations have come to realize that they take with them valuable knowledge Hildreth P. et al (1999). To counteract this, leadership factor is very important. Ramirez (2007) posits that management needs to support knowledge sharing in the organization and provide visible support to motivate the employees to share their knowledge.

Another knowledge management factor in literature is interdependence of tacit and explicit knowledge. Oinas-Kukkonen (2004) argues that much of the innovation created and accumulated in a firm is actually based on tacit knowledge. Malhotra (2001) states that the dominant conception of Information System (IS) based organizational knowledge system is constrained by the very nature of the knowledge creation process: it ignores the tacit and explicit dimensions of knowledge creation. Malhotra further argues that knowledge resides in the user and not in the collection of information and it is how the user reacts to a collection of information that matters. Pollard (2005) argues that the challenges faced today in getting people to share what they know and to collaborate effectively are not caused or cured by technologies, but are cultural impediments. It is extremely difficult to change people's behaviors (they usually exist for a reason), so the solutions need to accommodate these behaviors, and these cultures, rather than trying to 'fix' them (Pollard, 2005).

\section{Knowledge Management in Profit and Non profit in Organization}

In a given organization, knowledge management refers to identifying and leveraging the collective knowledge within it in such a way to help the organization compete (Alavi \& Leidner 2001). Knowledge management increases innovativeness and responsiveness. According to Davenport and Prusak (1998) most projects have one of the three aims:

First, to make knowledge visible and show the role of knowledge in an organization mainly through maps, yellow pages, and hypertext tools. Second, to develop a knowledge intensive culture by encouraging and aggregating behaviors such as knowledge sharing (as opposed to hoarding) and proactively seeking and offering knowledge. Finally, to build a knowledge infrastructure, not only a technical system, but a web of connections among people given space, time, tools, and encouragement to interact and collaborate.

\section{Knowledge Management Practices}

A research carried in Canada identified eighteen KMP which they clustered into six categories. These six categories include leadership, knowledge capture and acquisition, training and mentoring, policies and strategies, communications and incentives. (Earl, 2001).

Earl found the following report of the six categories: First, Leadership: Knowledge management practices are a responsibility of managers and executives and it is the explicit criteria for assessing worker performance. Also, KMP is a responsibility of nonmanagement workers and a responsibility of the knowledge officer or knowledge management unit. 
Second, Knowledge Capture and Acquisition: Firms capture and use knowledge obtained from other industry sources such as industrial associations, competitors, clients and suppliers and from public research institutions including universities and government laboratories. Firms are dedicated resources to detect and obtain external knowledge and communicate it in the firms and encourage workers to participate in project teams with external experts.

Third, Training and Mentoring: Firms encourages experienced workers to transfer their knowledge to new or less experienced workers and provide informal training related to knowledge management. Again, firms encourage workers to continue their education by reimbursing tuition fees for successfully completed work-related courses and offers offsite training to workers in order to keep skills current. Moreover, firms provide formal training related to knowledge management practices and uses formal mentoring practices, including apprenticeships.

Fourth, Policies and Strategies: Firms use partnerships or strategic alliances to acquire knowledge and policies or programs intended to improve worker retention. It includes value system or culture intended to promote knowledge sharing and written knowledge management policy or strategy.

Fifth, Communications: Workers share knowledge by preparing written documentation such as lessons learned, training manuals, good work practices, articles for publication, etc.(organizational memory). Moreover, workers share knowledge by regularly updating databases of good work practices, lessons learned or listings of experts and workers share knowledge in collaborative work by project teams that are physically separated ("virtual teams").

Sixth, Incentives: Knowledge sharing is rewarded with monetary and non monetary incentives.

The above survey was concerned with profit organizations in Canada over seven years ago and was not concerned with non profit organizations. However, the current study adapted and utilized the six categories of KMP in formulation of research questionnaires.

\section{The Research}

This research involved 16 non profit organizations constituting a 23 percent and 53 profit organizations representing $77 \%$ participated which translated to 69 respondents with a response rate of 100 percent turn up of the organizations that participated). The inference made here is that both organizations were positive during the exercise.

\section{Effectiveness of Knowledge Creation and Management in Organizations in Nairobi- Kenya}

This section is divided into five parts: A-E. Part A. Tacit knowledge is captured and transformed in explicit knowledge. Out of the 69 organizations interviewed none agreed that tacit knowledge is very effective. While 5 of the organizations concurred that it is 
effective. Twenty-one said it was somewhat effective, whereas greater number representing 43 organizations said that not at all effective. Part B. Technology (web, internet, telephone) is used to share and store (database) knowledge created. Twentythree organizations said that it is very effective, while 30 said it is effective. Fifteen deliberated that it was somewhat effective against one that said not at all effective.

Part C: Technology (web, internet, telephone) help the working community to reach a consensus and better comprehend issues related to work at hand. Eight organizations responded that it was very effective, while 16 answered that it was effective. Whereas twelve agreed that it was somewhat effective, 33 said that it was not all effective. Part D: technology (web, internet, telephone) increases the professional capabilities of the working community and support collaboration. Twelve participants responded that it was very effective against 17 that said it was effective. Also 17 said that it was somewhat effective against 23 that said it was not all effective. Part E: workers have a large access to the technology used to create knowledge. Only 5 of the respondents agreed that it is very effective, while twenty saw it was effective. Eighteen organizations answered that it was somewhat effective against 25 that said it was not at all effective. The deduction made here is that most of the organizations have no idea of knowledge creation and management within their organizations.

\section{KMP policies and strategies in organizations in Nairobi-Kenya}

This segment measures the use of formal, informal and everyday knowledge management practices. It is divided into four parts: Policies and strategies; leadership; incentives and communication.

\section{Policies and strategies}

Part A: has a written knowledge management policy or strategy: five organizations said that it was in use before 2000, while 5 said it has been used since 2000. Some 30 organizations plan to use in the next 24 months, whereas 39 don't know/not applicable. Part B: has value system or culture intended to promote knowledge sharing: some nine organizations concurred that it was in use before 2000 and some other nine said that it has been used since 2000. A group of organizations amounting to 36 said that they intend to use it in the next 24 months, against 15 who do not plan about knowledge management. Part $C$. has policies or programs intended to improve worker retention. Four organizations said that it has been in use before 2000 and 18 said that it has been in used since 2000. More organization, 28 in number said that they have plan to use within the next 24 months, while 19 organization showed no signs of ever using it. Part D: Uses partnerships or strategic alliances to acquire knowledge. Thirteen organizations agreed that it has been in use before 2000, while 17 concurred that it was used since 2000. Plan to use it in the next 24 months was voted in by 23, while 16 have no idea of knowledge management. The study found that capturing and transforming knowledge is important technology; however most organizations do not use it.

\section{Leadership}

This part seeks to know who is responsible for knowledge management practice. It is divided into four sections: A-D. Section A: A responsibility of managers and executives: 
eighteen organizations said that it is the responsibility of the managers and the executives to manage knowledge. Eighteen organizations, said that knowledge management has been in use since 2000 and another 18 consignments of organizations plan to use it in the next two years. Another group consisting of 15 organizations thinks the responsibility of managers and executives is not at all effective for knowledge management. Section B: A responsibility of non-management workers. As a result, few organizations in Kenya feel that Non-Managers could take that responsibility. For instance, 6 organizations believe that it is very effective, 6 other organizations said that it is effective, whereas most of the organizations accounting to 48 have reservations on such responsibility to non-managers. A group of 9 organizations sense that it is not at all effective.

Section C: a responsibility of the knowledge officer or knowledge management unit: 6 of the interviewed organizations said that it has been in use before 2000 and thirteen said it has been in use since 2000. A further 8 organizations did plan to use it within the next 24 months and the majority, amounting to 42 , do not agree to give the knowledge officer or knowledge management unit the responsibility of knowledge management. Section D: explicit criteria for assessing worker performance: almost 20 of the respondents said that they have explicit criteria for assessing worker performance and it is effective or very effective. Another bunch of 20 organizations find it is somewhat effective; and 29 othersw do not find it effective.

\section{Monetary incentives:}

Over 80 percent of the respondents argued that they receive no incentives at all against $20 \%$ that receives. The inference made here is that monetary incentives to KM are rare in most organizations.

Figure 3: a pie chart showing the modes of monetary incentives administered by organizations

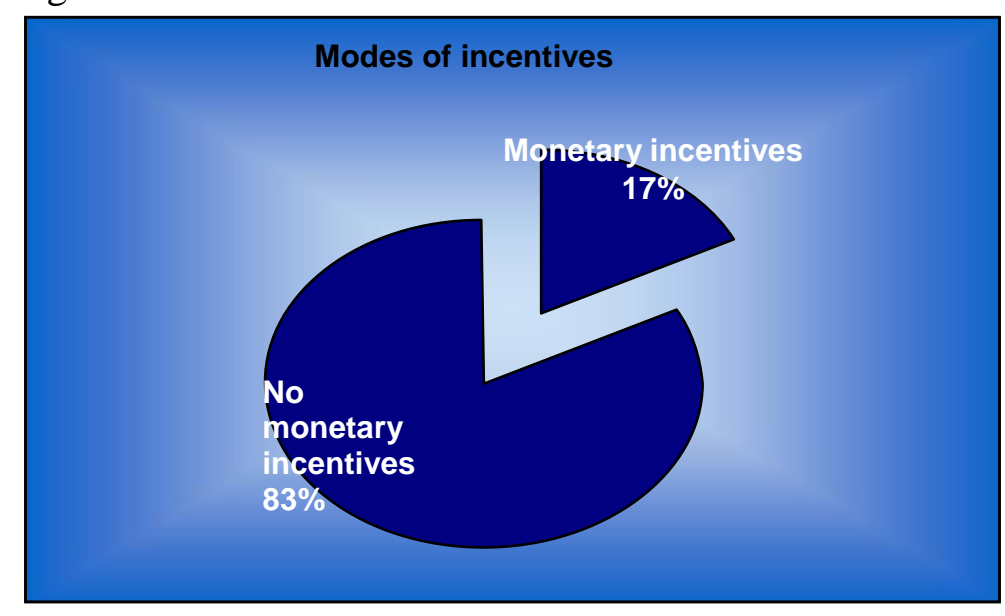

\section{Non-monetary incentives:}

Non-monetary incentives totaling to 75 percent was voted in as a way of rewarding KM against 25 percent that felt otherwise. 
Figure 4: a pie chart showing the modes of non-monetary incentives administered by organizations

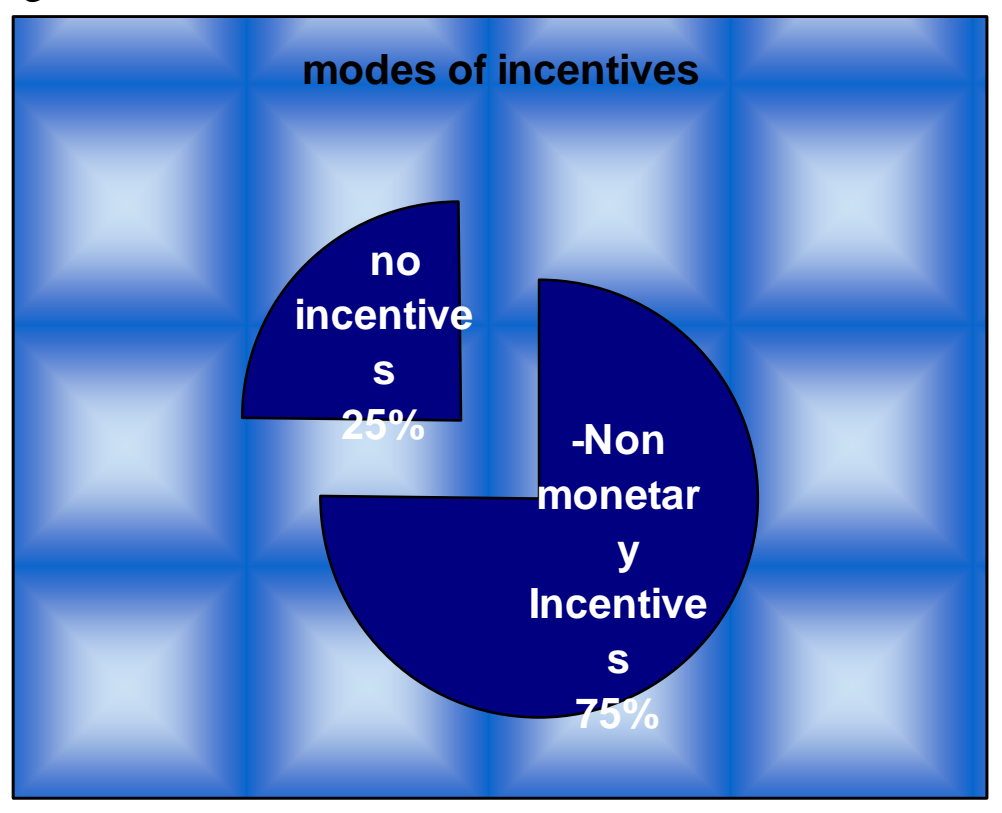

\section{Communication and KMP in organizations in Nairobi-Kenya: Use and re-use knowledge system}

A. regularly updating databases of good work practices, lessons learned or listing of experts. The study found that workers share knowledge or information by regularly updating databases of good work practices, lessons learned or listings of experts in organizations. Seven organizations carrying 10 percent said it is very effective, while 25 organizations holding 36 percent concurred that it is effective, 28 organizations translating to almost 40 percent said it is somewhat effective and 9 organizations having 13 percent say it is not at all effective. The deduction made here is that most of the organizations are not regularly updating databases of good work practices, lessons learned or listing of experts. Knowledge management is just a routine and not a management tool.

B. Preparing written documentation such as lessons learned, training manuals, good work practices, articles for publication, etc (organizational memory). The study found that workers share knowledge or information by preparing written documentation such as lessons learned, training manuals, good work practices, articles for publication, etc in organizations. Out of 33 organizations representing 48 percent said it is very effective, while 30 organizations that are 44 percent say it is effective. Only 5 organizations, 7 percent said it is somewhat effective and with one organization (that is 1 percent) said it is not at all effective. The conclusion made here is that knowledge is not updated regularly among some organizations and of course fails to utilize knowledge capturing system. 


\section{Knowledge capturing system}

C. facilitating collaborative work by projects teams that are physically separated (virtual team) Workers share knowledge or information by facilitating collaborative work by projects teams that are physically separated (virtual team). Out of the 69 organizations interviewed 26 organizations translating to approximately 38 percent declared it is very effective, with 37 organizations being roughly 54 percent say it is effective. Only 5 organizations at 7 percent said it is somewhat effective and a mere 1 organization pronounced it is not at effective at all. The deduction made here is that in most of the organizations, workers share knowledge or information in their different project teams.

Figure 5: a bar graph showing knowledge worker system.

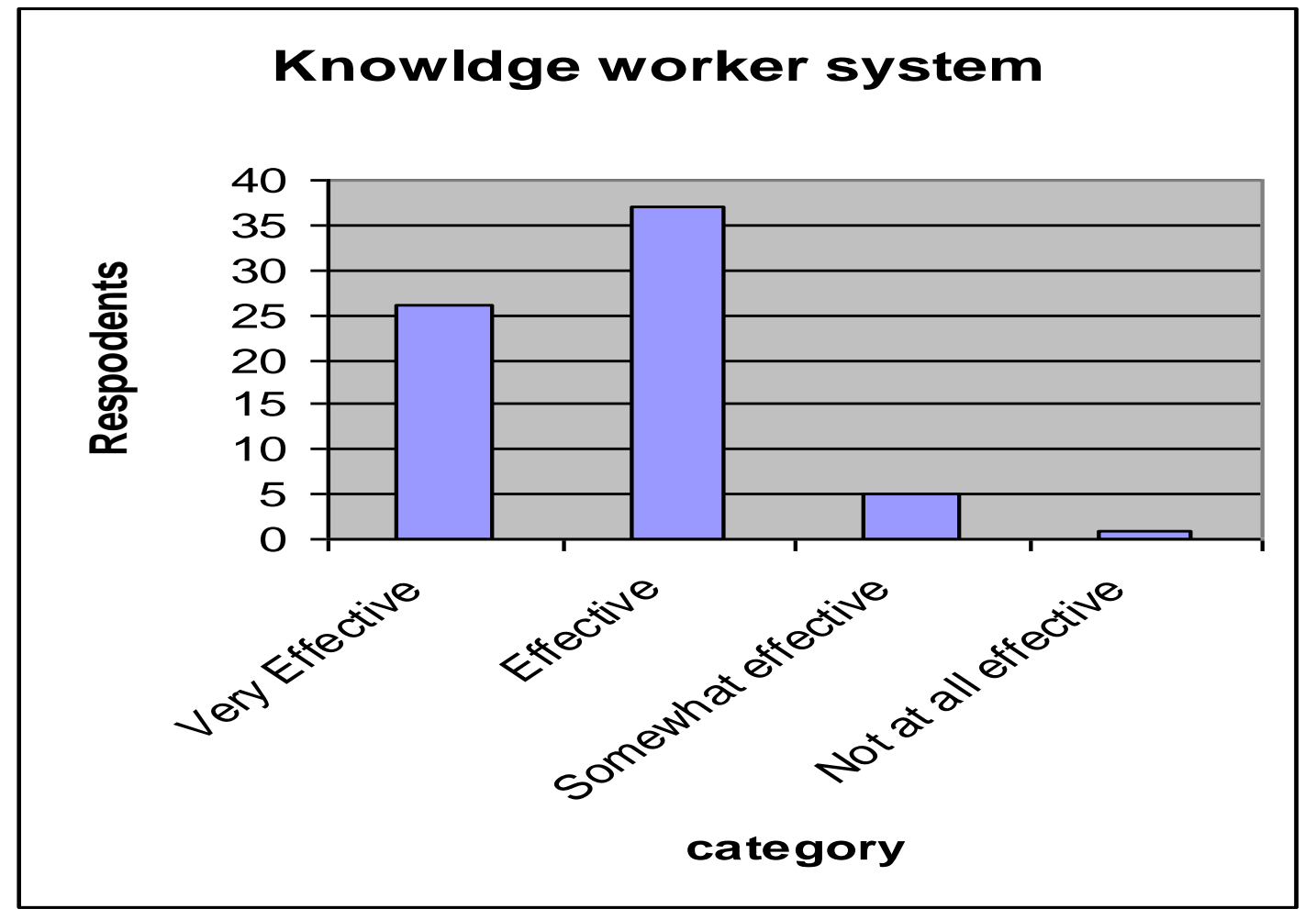

\section{Other knowledge management}

Over 87 percent amounting to 60 organizations did not find other knowledge management practices not listed in the questionnaire. But 9 organizations that are 13 percent found others knowledge management practices that involve clients/customers in decision-making, seminars, workshops, staff orientation, meetings, research and development, conference and training, market intelligent, rotational leadership between Managers and Non-managers.

\section{Reasons for using knowledge management practices in organizations within Nairobi} This section is divided into 12 parts: A-L. It was intended to seek the reason why knowledge management practices are used in organizations. Part A. To improve the 
competitive advantage of your organization. One of the reasons knowledge management practices are used in organizations in Nairobi is to improve the competitive advantage. Out of 69 organizations, 31 organizations said it is critical, while 32 organizations attested that it is important, 1 organization argued that it is somewhat important and 3 organizations suppose it is not at all important. The inference made here is that there is high competition in Nairobi and most of the organizations are striving for survival. Part B. To help integrate knowledge within your organization. The research established that one of the reasons knowledge management practices are used in organizations in Nairobi is to help integrate knowledge within the organization. The 27 organizations interviewed out of 69 said that it is critical, whereas 31 organizations indicated that it is important, only 4 organizations that argued that it is somewhat important and 5 organizations considered it is not at all important. The presumption made here is that knowledge management practices are relevant in collecting and using new idea in the organizations in Nairobi.

Part C. To improve the capture and use of knowledge from sources outside your organization. One of the reasons knowledge management practices are used in organizations in Nairobi is to improve the capture and use of knowledge from sources outside the organization. In fact 19 organizations said it is critical, 36 organizations confirmed that it is important, 6 organizations argued that it is somewhat important and 6 organizations supposed it is not at all important. Part D. To improve sharing or transferring of knowledge. Another reason why knowledge management practices are used in organizations in Nairobi is to improve sharing or transferring of knowledge. A number totaling 21 organizations interviewed said it is critical, 35 organizations made plain that it is important, 8 organizations did say that it is somewhat important and 3 organizations believe it is not at all important.

Part E. To increase efficiency by using knowledge to improve organization's performance. The reasons why knowledge management practices are used in organizations in Nairobi is to increase efficiency by using knowledge to improve organization's performance. 37 organizations said it is critical, 22 organizations attested that it is important, 6 organizations said it is somewhat important and 2 organizations supposed it is not at all important. Part F. To protect your organization from loss of knowledge due to workers' departures. Major reasons why knowledge management practices are used in organizations in Nairobi is to protect organizations from loss of knowledge due to workers' departures. For sure 20 organizations said it is critical, 13 organizations attested that it is important, 13 organizations believed that it is somewhat important and 2 organizations believed it is not at all important.

Part G. To train workers to meet strategic objectives of your organization. The reasons why knowledge management practices are used in organizations in Nairobi is to train workers to meet strategic objectives of the organizations. In fact 26 organizations said it is critical, 30 organizations affirmed that it is important, 8 organizations believed that it is somewhat important and 3 organizations said it is not at all important. Part H. To increase worker acceptance of innovations. The reasons as to why knowledge management practices are used in organizations in Nairobi is to increase workers acceptance of innovations. Out of the 69 organizations interviewed, 22 organizations said it is critical, 35 organizations attested that it is important, 6 organization argued that it is somewhat important and 4 organizations believes it is not at all important. 
Part I. To improve worker retention. One of the reasons why knowledge management practices are used in organizations in Nairobi is to improve workers retention. 12 organizations said it is critical, 40 organizations marked that it is important, 9 organizations argued that it is somewhat important and 5 organizations believes it is not at all important. Part J. To identify and/or to protect strategic knowledge present in your organization. One of the reasons as to why knowledge management practices are used in organizations in Nairobi is to identify and/or to protect strategic knowledge present in the organizations. Twenty-one organizations said it is critical, 32 organizations answered that it is important, 11 organization marked that it is somewhat important and 3 organizations believes it is not at all important.

Part K. To ease collaborative work of projects or teams that are physically separated (i.e. different work sites). The reasons as to why knowledge management practices are used in organizations in Nairobi is to ease collaborative work of projects or teams that are physically separated (i.e. different work site). Out of 69 organizations interviewed, 16 organizations said it is critical, 34 organizations attested that it is important, 11 organizations answered that it is somewhat important and 6 organizations believed it is not at all important. Part L. To promote sharing or transferring knowledge. Out of 69 organizations interviewed, 25 organizations said it is critical, 28 organizations attested that it is important, 12 organizations answered that it is somewhat important and 4 organizations believed it is not at all important.

\section{Results for the knowledge management practices currently in use in organizations in Nairobi-Kenya}

This section was intended to measure the results of using knowledge management practices in organizations and the effectiveness of results of using knowledge management practices. It is divided into 14 parts: A-N. Part A. increased our knowledge sharing horizontally (across departments, functions or business units). The results of using knowledge management practice in organizations in Nairobi are to increase knowledge sharing horizontally meaning across departments, functions or business unit. Out of the 69 organizations interviewed, 23 organizations said it is effective, 28 organizations answered that it is important, 12 organization said that it is somewhat important and 4 organizations believes it is not at all important. Part B. Increased our knowledge sharing vertically (up the organization hierarchy). Another result of using knowledge management practices in organizations in Nairobi is to increase knowledge sharing vertically meaning upward the organizational hierarchy. Twenty organizations said it is effective, 30 organizations affirmed it is important, 14 organizations said that it is somewhat important and 3 organizations do not value it at all. The inference made here is that most of the organization value horizontal and vertical sharing of knowledge.

Part C. Improved worker efficiency and/or productivity. Another result of using knowledge management practices in organizations in Nairobi is to improve worker efficiency and/or productivity. 12 organizations said it is effective, 27 organizations supposed that it is important, 14 organizations affirmed that it is somewhat important and 4 organizations believed it is not at all important. 
Part D. Improved skills and knowledge of workers. The result of using knowledge management practice in organizations in Nairobi is to improve skills and knowledge of workers. Twenty organizations said it is effective, 31 organizations answered that it is important, 13 organization said that it is somewhat important and 3 organizations believes it is not at all important. The study deduct majority of the organizations interviewed use knowledge management to improve worker efficiency and/or productivity.

Part E. Increased our number of markets or sponsor (more geographic location). One of the results of using knowledge management practice in organizations in Nairobi is to increase number of markets or sponsor (shareholders). Out of the 69 interviewed organizations, 18 organizations said it is effective, 20 organizations attested that it is important, 22 organizations argued that it is somewhat important and 4 organizations said it is not at all important. Part F. Improved client, customer or stakeholder relation. Using knowledge management practice in organizations improves client, customer or stakeholder relation. Twenty-one organizations said it is effective, 31 organizations attested that it is important, 11 organizations argued that it is somewhat important and 4 organizations believes it is not at all important. The deduction made here is that most of the organizations use it to improve relations.

Part $G$ Helped us add new products or services. One of the results of using knowledge management practice in organizations in Nairobi is to help add new products, services or ideas. Out of the 69 organizations interviewed, 15 organizations said it is effective, 28 organizations answered that it is important, 20 organization affirmed that somewhat important and 4 organizations believes it is not at all important. The study deducted that most of he organizations see that knowledge management help to add new products and services.

Part H. Increased our adaptation of production or services. One of the results of using knowledge management practices in organizations in Nairobi is to increase adaptation of production or services. Nineteen organizations said it is effective, 23 organizations attested that it is important, 22 organizations answered that it is somewhat important and 5 organizations affirmed it is not at all important.

Part I. Increased flexibility in production and innovation. A result of using knowledge management practice in organizations is to increase flexibility in production and innovation. 14 organizations said it is effective, 31 organizations attested that it is important, 21 organizations argues that it is somewhat important and 3 organizations answered that it is not at all important. Part J. Prevented duplicate research and development. Another result of using knowledge management practices in organizations is to prevent duplication of research and development. Out of the 69 organizations interviewed, 16 organizations held that it is effective, 17 organizations alleged that it is important, 23 organizations said that it is somewhat important and 11 organizations believed it is not at all important. The inference made here is that majority of the interviewed organizations said it is important to use knowledge management to Increase 
flexibility in production and innovation and to avoid research duplication and development.

Part K. Improved our organizational memory. One of the results of using knowledge management practice in organizations is to improve organizational memory. Seventeen organizations held that it is effective, 27 organizations assumed that it is important, 14 organizations argued that it is somewhat important and 9 organizations believed it is not at all important. Part L. Increased our ability to capture knowledge from research institutions including universities and government laboratories. The results of using knowledge management practice in organizations are to increase ability to capture knowledge from research institutions including universities and government laboratories. Seventeen organizations held that it is effective, 24 organizations supposed that it is important, 14 organizations argued that it is somewhat important and 12 organizations believed it is not at all important. The research deduct that knowledge management improves organizational memory and increase ability to capture knowledge from government and university institutions.

Part M. Increased our ability to capture knowledge from other business enterprises, organizations, technical literature, etc. One of the results of using knowledge management practice in organizations is to increase ability to capture knowledge from other business enterprises, organizations, and technical literature. Nineteen organizations said that it is effective, 23 organizations attested that it is important, 22 organizations held that it is somewhat important and 5 organizations believed it is not at all important. Part N. Improved involvement of workers in the workplace activities. Another result of using knowledge management practice in organizations in Nairobi is to improve involvement of workers in the workplace activities. Out of the 69 respondents, 25 organizations articulated that it is effective, 30 organizations attested that it is important, 10 organizations argued that it is somewhat important and 4 organizations believed it is not at all important. The study infers that several of the respondents were positive it increased the ability to capture knowledge and improved involvement of workers.

Figure 6: a bar graph showing groups responsible for KMP 


\section{Responsible for KMP}

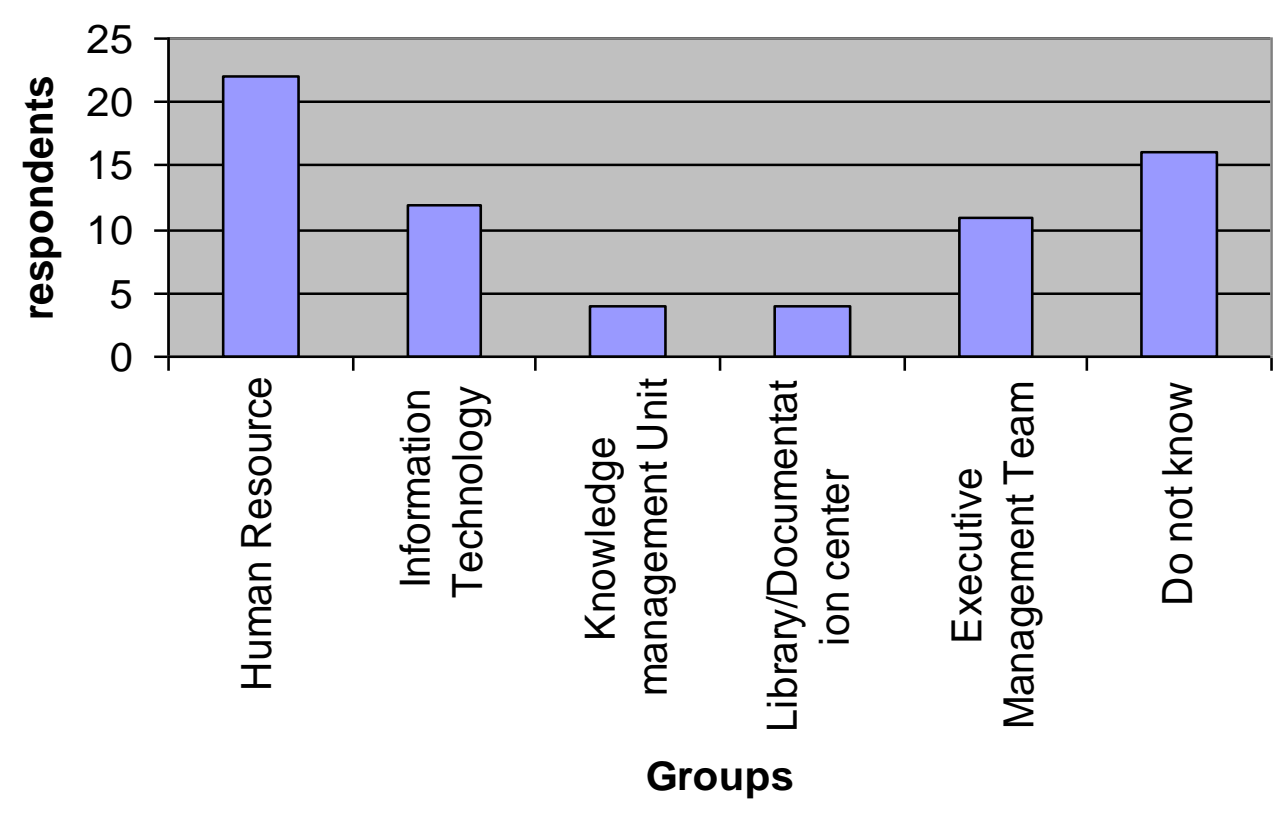

Do you measure the effectiveness of your organization's knowledge management practices?

Only 12 organizations representing 17 percent said that they measure the effectiveness of organizations' knowledge management practices, against 83 percent who do not (see figure 7).

Figure 7: a pie chart showing the percentage of organizations that measures KMP

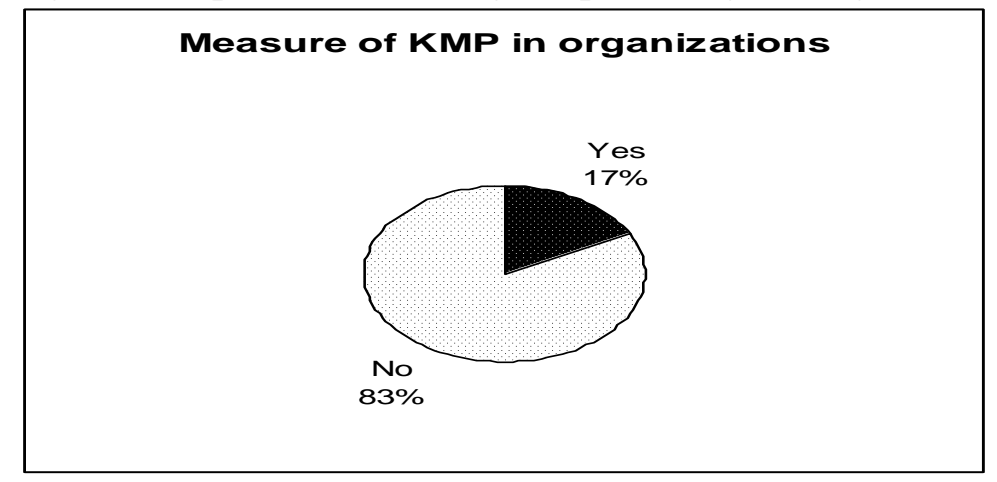




\section{Resistance in Implementing KMP}

45 organizations representing 65 percent said they experience significant resistance when implementing knowledge management practices and whereas 24 organizations representing 35 percent held that they do not experience resistance (see figure 8 ).

Figure 8: a pie chart showing the percentage of resistance to KMP

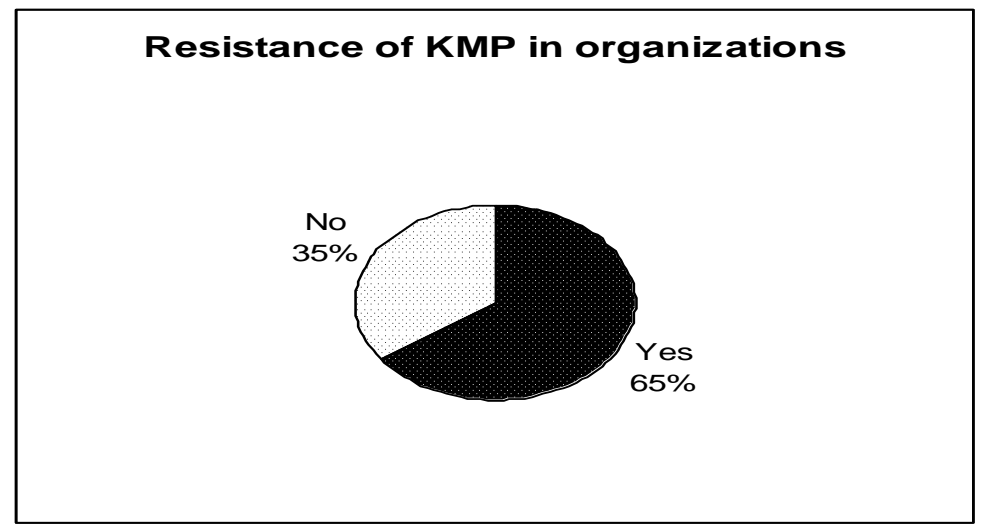

\section{Key factors that motivate knowledge management within organizations}

All of the 69 organizations said that the following aspects would motivate organizations to implement KMP:

1. Information overloads problems within your organization.

2. Difficulty in capturing workers' undocumented knowledge (know-how).

3. Use of knowledge management tools or practices by competitors.

4. Loss of market share or sponsor.

5. Loss of key personnel and their knowledge.

6. Difficulties in incorporating external knowledge.

\section{Non profit and profit organizations}

Both non profit and profit organizations were involved in the exercise. Most of the organizations falling under the category of micro size and small size were many. The argument here is that most of the Kenyan organizations are small in size and that creation of KMP is needed to develop them. The smallness of the organizations may be an indication that the implementation of KMP in organizations in Nairobi is ignored. This study recommends that small organizations should capture knowledge, both tacit and explicit, within their organizations.

\section{KMP and Technology}

The KMP are largely dependent on technology. Almost all of respondents said that they are using technology (web, internet, telephone) to capture, share and transfer information or knowledge. This is dependent to the size of the organization, from the micro organization (1-19 workers) to the large one (at least 250 workers). Also the study found that almost all of the organizations have governing policies and strategies that govern 
them. The study recommends that these organizations need to be versed in new technology and their workers need to be computer literate.

\section{Hierarchy Model of Leadership and Incentives}

The hierarchy model of leadership sought to know who is responsible for knowledge management. More than half of the respondents said that it is the responsibility of the managers and executives to create, promote, manage and share knowledge. This type of organization leadership and culture make less effort to implement strategies for workers retention. Also, it fails to have explicit criteria for assessing knowledge management in workers, less monetary incentives but some or non monetary incentive. This study recommends that by using effective appraisal performance and measurement, organizations should utilize both monetary and non-monetary incentives to both motivate workers in production of new knowledge.

\section{Organizational Culture}

The organizational culture hobbles the effectiveness of knowledge creation and management within the organization. Some respondents commented that knowledge management is only for managers while staff and others are not involved. This study therefore recommends that there is need for a culture/system where everybody can be involved. Other respondents said that organizational politics are major factors that hinder knowledge management practices in organizations in Nairobi-Kenya. Therefore the study recommends that destructive politics should be ignored in organizations.

\section{Communication and KMP in Organizations in Nairobi}

Most of the organizations interviewed have their way of capturing knowledge. For instance, some organizations capture knowledge articles, training, reports, database updating among others. Nevertheless, some organizations do not understand what KMP entails, how to implement it and how to gain from it in the rapidly changing environment. Therefore, the study recommends that all profit and non-profit organizations should seek the best ways to capture both tacit and explicit knowledge.

\section{Use of KMP and Measuring Its Effectiveness}

Some organizations in Nairobi-Kenya are applying various systems to measure the effectiveness of knowledge management. However, it is not consistence and need to be reactivated. This will be done through:

1. Remitting of reports in various departments for valuation

2. Retention rate of members

3. Going back to the base-root of where they have started and then assess how far they have gone, what the organization has gained due to the use of knowledge management and what has been lost due to lack of effective knowledge management.

4. Formally and informally checking out knowledge sharing in the organization

5. Questionnaires and consistent observation

6. Assessing the ability of workers to deliver 
7. Team evaluation meeting and follow up

8. Regular survey

The study, therefore recommends that these organizations need to:

1. Increase competition in the market.

2. Have constant changes in the market.

3. Be consistent in product development.

4. Have regular meetings to share knowledge.

5. Ensure rotational leadership from the managers, executives, including nonmanagement workers.

6. Have researchers' constructive workshops.

7. Attend conferences that bring people together in order to build relationships and uncover needs, and share ideas and evidence that will let them do their jobs better. It is the human force that makes knowledge transfer (the movement of knowledge from one place or group of people to another) more effective.

8. Broker knowledge: brokering of knowledge needs a supportive organization where there is a collaborative environment, sufficient resources for the job, processes to identify and capture knowledge generated by both employees and outside parties, and a desire to build intellectual capital.

The study has discussed several ways in which knowledge can be created and utilized. Knowledge management practice is both horizontal and vertical in organizational leadership and each person within the organization should be given equal opportunity. Also organizations should create ways to retain workers and tap both explicit and tacit knowledge for the betterment of their organization. The next chapter makes observations and conclusions.

\section{Summary of the Major Findings}

Knowledge Management Practices definitions circles around the following concepts: knowledge identification, creation, capturing, sharing and transferring of knowledge for better performance in organizations. Knowledge is composed of both tacit (undocumented, hidden in the mind of a person) and explicit (documented, easy to express). Knowledge is a cognitive asset that human being receives from experience and sometimes after a long period of time. Knowledge is created through a process called "hierarchy knowledge". This hierarchy knowledge is constituted at the lower level by data, middle level by information and then knowledge.

Knowledge Management Practices is a new discipline as earlier indicated. It takes its roots in the shift from the old way of doing business called "old world of business" to new way of doing business called "new world of business." The first was characterized mainly by a predictable and stable environment. The second is characterized by a volatile environment with a rapidly changing and high level of competition. In this new world of business, organizations adopt Knowledge management. This is because it helps organizations deal with increased complexity and represents a key opportunity to 
leverage knowledge assets for achieving substantial savings, significant improvements in human performance, and competitive advantage.

Although much literature exists on knowledge management no one has undertaken a research on the KMP in organizations in Nairobi-Kenya. The research did reveal that some organizations do use KMP to some extent. Various ways to create and capture KMP have been identified. Nevertheless, KMP though practiced is not well understood by most organizations within Nairobi. In fact most of the challenges faced by organizations in Nairobi are how to create and implement KMP as part of organizational culture, organizational strategy and organizational leadership. Though most organizations said that they use Technology (web, internet, telephone) there is need for a synergy with other enablers' factors (organizational culture, organizational strategy and organizational leadership).

In the implementation of KMP in organizations in Nairobi, technology is largely used in KMP but does not maximize the use of knowledge management because culture, leadership and strategy are ignored in the process. There is evidence that organizational culture hobbles the effectiveness of KMP in organizations in Nairobi. Organizational politics, ethnicity diversity, emotions, values do not favor organizations in Nairobi to capture tacit knowledge and transform it to explicit knowledge. This lack of tacit knowledge in organizations in Nairobi is very crucial. Most of the challenges faced by organizations in Nairobi, such as organizational culture, organizational strategy and organizational leadership can be overcome by effectively implementing KMP.

\section{Recommendations}

The study recommends that organizations should find out how to benefit from culture diversity to improve KMP in Nairobi.

Organizations should become a learning center and provide facilities for knowledge management. Some of the facilities include workshops, knowledge management conferences and refresher courses, among others. When an organization becomes a resource center, the staff will build relationships among themselves, uncover overlooked organizational needs, share ideas and evidences that generate new ideas which enhance organizational performance and creation of knowledge. During these sessions new knowledge will be recorded and stored for use and reuse.

Knowledge management creation must be both vertical and horizontal (executives and non-executives) in organizational leadership. The study recommends that all profit and non-profit organizations should seek the best ways to capture both tacit and explicit knowledge. This study recommends that by using effective appraisal performance and measurement, organizations should utilize both monetary and non-monetary incentives to both motivate workers in production of new knowledge. Non-profit and profit organizations in Nairobi should reinforce the creation of knowledge by integrating effective leadership, strategy and culture in their organizations. 


\section{References}

Alrawi, A. K. (2007). "Knowledge Management and the Organization's Perception: A Review." Journal of Knowledge Management Practice, VIII, No. 1, 32-48.

Alavi, M. \& Leidner, D. E. (2001). "Review: Knowledge Management and Knowledge Management System: Conceptual Foundations and Research Issues."

MIS Quarterly, Vol. XXV, N0 1, 98-115.

Asllani, A. \& Luthans, F. (2003). "What knowledge Management Really Do: An Empirical and Comparative Analysis." Journal of Knowledge Management, VII, N0 3, 16-53.

Banhenyi, S. (2007). "A Knowledge Engine Driving Africa's Development." A paper presented in KMAfrica, (online) available at $<$ www.kmafrica.info/news, 5-18.

Chatterjee, J. (2002). "Knowledge Based Strategies \& Research Directions in India." Kware Conference Proceedings, IEEE (online) available at < www.iitk.ac.in, July

CHSRF Report. (2003). "The theory and practice of knowledge brokering in Canada's Health System." (online) available at $<$ www.chrsf.ca. , Ottawa, 2003.1-46

Cortada, J. W. \& Woods, J. A. (1999). (eds.). The Knowledge Management Yearbook 1999-2000. London, GB: Butterwort Heinemann.

Davenport, T. H. \& Prusak, L. (1998). Working Knowledge. How Organizations Manage what They Know? Boston, MA: Harvard Business School Press.

De Rezende, J. L. \& De Souza, J. M. (2007) "Using knowledge Management Techniques to Improve the Learning Process through the Exchange of Knowledge Chains." Paper presented in the 11th International Conference on Computer Supported Cooperative Work in Design, Institute of Mathematics, Rio de Janeiro, RJ, Brazil, 681-686.

Earl, L. (2001). "Knowledge Management in Practice in Canada. Science, Innovation and Electronic Information Division.” N0. 07 (online) available at, http://www.statcan.ca. 1-14.

Frankfort-Nachmias, Chava \& Nachmias D. (1996).Research Method in the Social Sciences, Fifth Edition. London, GB: St. Martin Press.

Gammelgaard, J. (2007). "Why Not Use Incentives To Encourage Knowledge Sharing?" Journal of Knowledge Management Practice, VIII, No. 1, 46-58.

GDNet. (2006). "Knowledge Management Capacity for African Research Institutes and Networks: East Africa Workshop." GDNet Report, Kampala, Uganda: 4-9.

GDNet (2005). "Knowledge Sharing for Development: Africa Regional Program." Workshop Report, Cairo, Egypt:1-48.

Govil, R. ( 2007). "Data Management, Information Management, Knowledge Management" The World of Knowledge Management (online) Available at < http://kmlearning.blogspot.com, , 5-26.

Haggie, K. \& Kingston, J. (2003). "Choosing your Knowledge Management Strategy." Journal of Knowledge Management Practice, Vol. IV, 43-54.

Hick, R. C. et al. (2007). "The Transformations in the Five Tier Knowledge Management Transformation Matrix.” Journal of Knowledge Management Practice, VIII, No. 1, 10-18. 
Hick, R. C. (2007). “A Metaphor for Knowledge Management: Explicit Islands in a Tacit Sea." Journal of Knowledge Management, XI, N0 1, 1-9.

Hick, R. C. (2006). "The Five Tier Knowledge Management Hierarchy." Journal of Knowledge Management Practice, X, NO.1, 19-27.

Hildreth, P. et al. (1999). "Knowledge Management: Are We Missing Something? Information Systems - The Next Generation," Proceedings of the 4th UKAIS Conference. York, UK, (online) available at < http://www.cs.york.ac.uk., April, 347-356.

Holvand, I. (2003). Knowledge Management and Organizational Learning: An International Development Perspective. An Annotated Bibliograph.”, Working Paper,N0 224, London, GB: Overseas Development Institute, 224-229.

Ichijo, K. \& Ikujiro, N. (2006). Knowledge Creation and Management: New Challenges for Managers. New York, NY: Oxford University Press.

Ireri, J.W. \& Wairagu, A. M. (2007). "Bridging the "Knowledge-how' and the 'Knowledge-do' Gap in Public Health in Africa: From Traditions to E:AMREF's Role and Experiences in Health Information Dissemination." Paper presented at The Knowledge Management Africa (KMA) second biennial conference 2007, Nairobi, KE: 18-21.

JIU. (2004). "Knowledge Management at International Labor Organization.” Joint Inspection Unit INOTE/. GENEVA, 23.

Kakabadse, N. K. et al. (2003). "Reviewing the Knowledge Management Literature: Towards aTaxonomy." Journal of Knowledge Management, VOL. VII, N0 4, 75.

Kamau, P. M. (2007). "The Investigation of the Causes of Conflict between Borana and Gabra Communities of Northern Kenya and Ways of Conflict Prevention and Reconciliation." MA Thesis, Africa Nazarene University.

Kenneth, A. (1962). The Economic Implications of Learning by doing Review of Economic Studies. Princeton, N J: Princeton University Press.

KMA, (2007). "Conference Knowledge Management Africa, Knowledge to remobilize Africa." (online) available at < www.kmafrica.info/news, 1-96.

Laszlo, K. C. 2001 "The Evolution of Business: Learning, Innovation and Sustainability in the 21st Century." Paper presented at the 45th Annual Conference of the International Society for the Systems Sciences, 7 Asilomar, California, USA: 6-62.

Liew, A. (2007). "Understanding Data, Information, Knowledge and Their InterRelationships." Journal of Knowledge Management Practice, VII, No. 2, 102-122.

Malhotra, Y. (1998). "Knowledge Management, Knowledge Organizations and Knowledge Workers: a View from the Front Lines." Maeil Business Newspaper, (online) available at < www.brint.com, February 19, 1-32.

Malhotra, Y. (2001). "Organizational Controls as Enablers and Constraints in Successful Knowledge Management Systems Implementation." PA, (online) available at <: www.brint.org. 326-36.

Malhotra, Y. et al. (2000). "Knowledge Management for E-business Performance: Advancing Information Strategy to 'internet time'", The Executive's Journal, XVI, (online) available at: < www.brint.com., 5-16. 
Malhotra, Y. \& Galletta, D. F. (2003). "Role of Commitment and Motivation in Knowledge Management Systems Implementation: Theory, Conceptualization, and Measurement of Antecedents of Success." Proceedings of the Hawaii International Conference on Systems Sciences (HICSS 36) (online) available at $<$ www.brint.org., 1-62.

McElroy, M. (2001). "Second-Generation Knowledge Management," Paper presented on Knowledge Management Consortium, Macroinnovation Association, KM World, (online) available at $<$ www.macroinnovation.com. 15-37.

Ndugo, S. et al, (2007). "Indigenous Tools of Capturing Knowledge: Trachoma Bead System." Paper presented at The Knowledge Management Africa (KMA) second biennial conference, Nairobi, KE: 1-19.

Nonaka, I. \& Takeuchi, H. (1995). The Knowledge-Creating Company. New York, NY: Oxford University Press.

Oinas-Kukkonen, H. (2004). "The 7C Model for Organizational Knowledge Sharing, Learning and Management," Fifth European Conference on Organizational Knowledge, Learning and Capabilities (OKLC'04), Innsbruck, Austria: 2-3, $1-13$.

Ondari, O. E. \& Minishi, M. M. (2007). "Enhancing Governance, Performance Effectiveness and Capacity to Deliver Basic Government Services in Sub-Sahara Africa through Knowledge Management." Paper presented at The Knowledge Management Africa (KMA) second biennial conference 2007, Nairobi, KE: $1-15$

Pollard, D.(2005). "Knowledge Sharing and Collaboration 2015.” Paper presented on Connect and Collaborate Conference, September 29, 1-38.

Prescott, J.E. et al. (2001). Proven Strategies in Competitive Intelligence: Lessons from the Trenches. New York, NY: Wiley.

Ramirez, A. (2007). "To Blog or not to Blog: Understanding and Overcoming the Challenge of Knowledge Sharing." Journal of Knowledge Management Practice, VIII, 38-49.

Rippon, A. E, (2002). A strategic Approach for Not-For-Profit Organizations. Ph.D. Thesis, Faculty of Economic and Management Sciences, Johannesburg, SA: Johannesburg University.

Sharp, D. (2004). “Thriving in World of Hyper-competition” Business Time, (online) available at $<$ www.businesstimes.on.ca , August, 1-7.

Sigala , M. \& Chalkiti, K. (2007). "Improving Performance through Tacit Knowledge Externalization and Utilization. Preliminary findings from Greek Hotels." International Journal of Productivity and Performance management, LVI, No. 5/6, 401-465.

Stover, M. (2004). "Making Tacit Knowledge Explicit: the Ready Reference Database as Codified Knowledge.” Journal of Knowledge Management, XXXII, Number 2, 164-173.

Thitithananon, P. et al. (2007). "Knowledge Management is a Perfect Education Development Tool: is Thailand's Higher Education Really Ready to embrace It?" Journal of Knowledge Management Practice, VIII, No. 2, 1-26. 
Warren, J. et al. (2006) “Organizational Development NASA-KSC.” Paper presented In NASA KM Conference, March 2-3.

Wickramasinghe, N. et al. (2003). "Do we practice what we preach? Are knowledge management systems in practice truly reflective of Knowledge Management Systems in Theory?" Business Process Management Journal, IX, N0 3, 286-301. 